Published online 2017 April 13.

Abstract

\title{
New Guidelines in Management of Thyroid Nodule When to Biopsy and When to Follow
}

Bijan Bijan ${ }^{1, *}$

${ }^{1}$ Professor of Nuclear Medicine and Radiology Radiology and Nuclear Medicine / PET Divisions, University of California Davis Medical Center, Sacramento, California, USA

"Corresponding author: Bijan Bijan, MD, MBA, CIIP, Professor of Nuclear Medicine and Radiology Radiology and Nuclear Medicine / PET Divisions, University of California Davis Medical Center, Sacramento, California, USA. E-mail: bbijan2002@yahoo.com

Received 2016 December 21; Accepted 2017 February 08.

\begin{abstract}
Lack of unified system in characterizing and reporting thyroid nodules is deeply felt almost in every institution and is a source of confusion among diagnostic radiologists, pathologists, thyroid surgeons, oncologists, endocrinologists and interventionalists. Elaborate systems exist but they are not easy to use. Therefore many of those systems cannot be utilized widely in general radiology practice. A simplified approach to thyroid nodule is a crucial need to prevent unnecessary work up, follow up or procedures. A combination of TIRADS and ACR guidelines probably would strike a balance between high sensitivity with acceptable specificity.
\end{abstract}

This is an abstract presented in the 33rd Iranian congress of radiology (ICR) and the 15th congress of Iranian radiographic science association (IRSA).

Copyright (C) 2017, Tehran University of Medical Sciences and Iranian Society of Radiology. This is an open-access article distributed under the terms of the Creative Commons Attribution-NonCommercial 4.0 International License (http://creativecommons.org/licenses/by-nc/4.0/) which permits copy and redistribute the material just in noncommercial usages, provided the original work is properly cited. 